On each trial, reinforcement was available for a response on one of the two bars. The less frequently reinforced choice is denoted by $A_{1}$ and the other choice by $A_{2}$. The relative frequency of $A_{1}$ per session is denoted $P\left(A_{1}\right)$. The constant probability of reinforcement for an $A_{1}$ was $\pi=.3$. The sequence of reinforcements, typically changed each day, was obtained from a table of random numbers and was unrestricted except that the subsequence for Trials 68-100 was the same as for Trials 1-33. Rats 11 and 12 had one sequence and Rats 14, 15, and 16 another.

Every $S$ received magazine and bar training in the experimental chamber. Pretraining was terminated as soon as an animal singly alternated for approximately 10 trials. The number of reinforcements presented during pretraining ranged from 60 to 200 .

\section{RESULTS}

The learning curves of Rats 14,15 , and 16 appear in the top panel of Fig. 1. Over the first several sessions, $P\left(A_{1}\right)$ roughly approximated $\pi$. The learning curves for Rats 14 and 15 were sufficiently stable, over the first 21 and 26 sessions, respcctively, to enable the calculation of the relative frequency of $A_{1}$ for each of the 100 trials. The middle panel of Fig, 1 shows these data. As this panel shows, there was little, if any, within-session effect over these initial sessions: the relative frequency of $\mathbf{A}_{1}$ approximately equaled $\pi$ for each of the: 100 daily trials, for more than 2,000 trials. However, the bottom panel in Fig. 1 shows that a within-session effect had developed by the 50th session. The rate of the within-session change is quite high for Rats 14 and 15 but is more gradual for Rat 16.

Learning curves for Rats 11 and 12 were somewhat steeper than were those for Rats 14,15 , and 16 , shown in the top panel of Fig. 1. Like Rats 14, 15, and 16, the flat within-session curve that was obtained early in training from Rats 11 and 12 changed later to steep curves much like those for Rats 14 and 15 .

Averaging over steady-state behavior of the five rats, the relative frequency of $A_{1}$ on Trial 1 was .39 . Over Trials $1-4$, it was .26. But over Trials 90-100, it was only .06 .

\section{DISCUSSION}

The obtained learning curves are consistent with the view that initial performance by rats in discrete-trials probability-learning experiments using a correction procedure approximates probability matching, but that extended training generates performance more nearly approximating maximizing. However, the obtained within-session effect qualifies this view. The relative frequency of a particular choice on the early trials of terminal sessions approximated the reinforcement probability. Thus, it may well be that the matching obtained by Lauer \& Estes (1954) is a genuine effect and not the result of too little training. However, if such asymptotic matching is found only in nart of a session but disppears over trials after extended training, the linear operator model (Estes, 1964) still requires modification.

\section{REFERENCES}

CALFEE, R. C. Choice behavior during long-term probabilistic reinforcement schedules. Journal of Comparative \& Physiological Psychology, $1968,65,232-237$.

ESTES, W. K. Probability learning. In A. W. Melton (Ed.), Categories of human learning. New York: Academic Press, 1964. Pp. 89-128.

HICKSON, R. H. Response probability in a two-choice learning situation with varying probability of reinforcement. Journal of
Experimental Psychology, 1961, 62, 138-144. LAUER, D. W., \& ESTES, W. K. Observed and predicted terminal distributions of response probability under two conditions of random reinforcement. American Psychologist, 1954, 9, 413. (Abstract)

UHL, C. N. Two-choice probability learning in the rat as a function of incentive, probability of reinforcement, and training procedure. Journal of Experimental Psychology, 1963, $66,443-449$.

WITTE, R. S. Conditioned response probability in a T-maze. Journal of Experimental Psychology, 1961, 62, 439-447.

NOTE

1. This research was performed while the author was at Brown University; it was supported in part by a NSF Graduate Fellowship. The author would like to thank Dr. Richard B. Millward for his many helpful suggestions during the course of this research. The preparation of this manuscript was supported in part by a $\mathrm{MH}$ grant (No. 16928) to the author.

\title{
Orienting response of kittens with lesions of the superior colliculus ${ }^{1}$
}

THOMAS S. BROWN, Institute for Psychosomatic and Psychiatric Research and Training, Michael Reese Hospital, Chicago, Ill. 60616, and GERSHON BERKSON, Illinois State Pediatric Institute, Chicago, Ill. 60608

Kittens whose superior colliculi had been ablated showed a defect in the eye-fixation response but not in heart-rate or respiration-rate responses.

Dreher, Marchiafava, \& Zemicki (1965) have shown that ablation of the superior colliculus in adult cats reduces eye fixations markedly and also affects head movements, pupillary dilation, and EEG arousal. The purpose of this experiment was to examine the effects of lesions of the superior colliculus on eye fixation, heart rate, and respiration rate in the kitten. METHOD

The Ss were 16 mother-reared kittens, approximately 60 days of age at the time of testing. Five of the Ss had received bilateral ablation of the superior colliculus at 50 days of age. These animals were the $\mathrm{SC}$ group, and the remaining $11 \mathrm{Ss}$ were the control group.

The SC group received one-stage bilateral aspirations of the superior colliculus under Nembutal anesthesia $(30 \mathrm{mg} / \mathrm{kg})$. A bilateral crainotomy was performed over the posterolateral area of the skull, the posterior boundary of the bone removal being the tentorium. When the bone removal was judged sufficient, the dura was opened and the head of the animal was then rotated forward so that the animal faced downwards. The cerebral hemispheres were then gently retracted forward away from the bony tentorium by inserting strips of cottonoid between the tentorium and the posterior aspect of the hemisphere. The colliculi were thus visualized and aspirated. The wound was closed in anatomical layers, and the animal was treated with antibiotics.

Apparatus and Procedure

The animal was restrained in a holder that was placed in a $2 \times 2 \times 2 \mathrm{ft}$. sound-deadened cubicle from which external light was excluded. The animal faced the front wall of the cubicle, which served as the door and also as a stimulus panel. At S's eye level in the center of the door was a 0.25 -in.-diam peephole through which the animal could be observed from outside the cubicle. On either side of the peephole was a $3.5 \times 3.75$ in. rectangular stimulus panel whose center was $6.50 \mathrm{in}$. from the peephole. In these experiments, the panel to S's right was covered with opaque material. The other panel was covered with frosted glass which could be lit from behind two 6-W bulbs. In front of this panel was a 2.25-in.-diam disk which could rotate, and when it did so, an $89-\mathrm{dB}$ 
(re .0002 dyne $\mathrm{cm}^{2}$ ) buzzer was associated with the rotation. Addition of the sound was made necessary by the fact that, in preliminary work, it was found that the kittens did not respond to onset of the light and silent rotation of the disk. In the wall behind the animal and 18 in. off the floor was a small 10-W bulb. When this bulb was turned on, another buzzer $(82 \mathrm{~dB})$ near it sounded. Temperatures in the cubicle varied from $77^{\circ} \mathrm{F}$ to $80^{\circ} \mathrm{F}$ during the experiment, and the ambient sound level in the cubicle was about $74 \mathrm{~dB}$.

During the procedure, $S$ was connected to a Type R Dynograph (Beckman Instruments $C_{0}$ ), using couplers adapted for measuring skin resistance, heart rate, and, by use of a strain gauge, respiration. A separate channel was used for each of these measures. In addition, two event pens were included, one worked manually by $\mathrm{E}$ for indicating when eye fixations occurred and one that showed when either of the two stimulus combinations was on.

The $S$ was habituated to the experimental situation by being placed in the holder inside the cubicle during four 10 -min sessions prior to the first day of the experiment proper. The Ss were tested on 1 day.

On the test day, areas of the animal's legs were shaved and he was then brought to the experimental room. These areas and also the pads of his forefeet were cleaned with acetone. Dry zinc electrodes, 0.25 in. in diam, were attached to each forefoot pad and secured with foam rubber and adhesive tape, and a skin resistance reading was immediately made with a vacuum tube ohmmeter. Bare wire electrodes were attached to the animal's right foreleg and left hindleg for measuring heart rate. The animal was then tied in the holder, with his chest and abdomen resting on a blood-pressure bladder that was connected to a strain gauge for measuring movements and respiration. These skin-resistance, heart-rate, and respiration leads were then connected to the Dynograph, another skin resistance reading was taken, and the door of the cubicle was closed.

On the test day, a resting record was taken during the ensuing $5 \mathrm{~min}$, with measures of respiration and heart rate taken continually and skin resistance measured at $1 \cdot \mathrm{min}$ in tervals.

Thirty seconds following completion of the resting period, a series of six flash-buzzer combinations, originating from the light behind the animal, was begun. The stimulus was presented manually by the $E$ so that its duration was somewhat variable but approximately $0.50 \mathrm{sec}$ long. Intervals between stimuli also varied because an attempt was made to present the flashes when the physiological

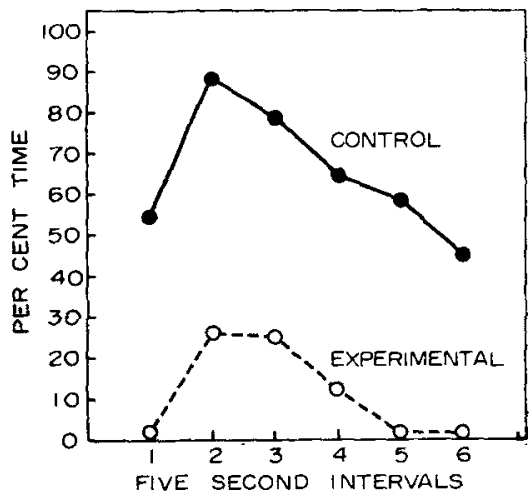

Fig. 1. Per cent time of eye fixation by the $\mathrm{SC}$ and control animals during the first trial.

record was stable. However, it was ordinarily possible to keep the intervals at about $33 \mathrm{sec}$. Prior to each flash, a skin resistance reading was made.

A series of six $30-$ sec presentations of the light, buzzer, and disk combination in front of the animal began $30 \mathrm{sec}$ after the flash series. Again, skin resistance was measured prior to the stimulus, and $33 \mathrm{sec}$ separated trials. During this series, the $E$ depressed a button controlling an event pen when the rotating disk was reflected in the pupil of the S's eyes.

\section{RESULTS}

The lesions of the SC spared the most anterior portions of the colliculus in all cases. In three of the five animals, the removal of the SC was virtually complete with the exception of the anterior portion just mentioned. For the other two Ss, the colliculus on the right side was relatively intact, and the lesion was placed at the junction of the superior and inferior colliculi. In two animals, there was unilateral extension into the tegmentum. In one animal, there was midline cortical damage dorsal to the superior colliculus.

Analysis of heart-rate and respiration records showed that the stimulus produced

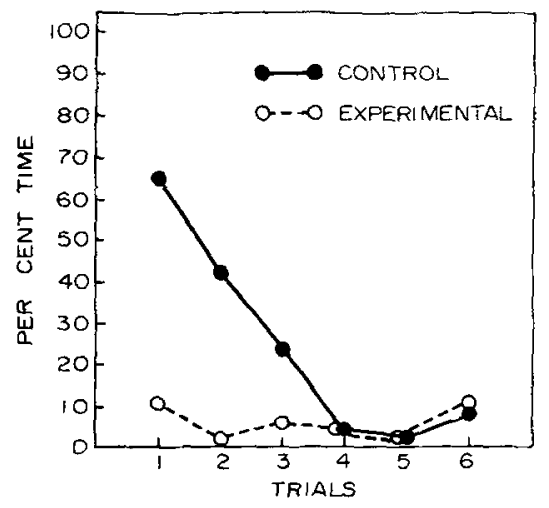

Fig. 2. Per cent time eye fixation by the $S C$ and control animals over trials. a response in all instances except the phasic heart-rate responses. However, in no case was the effect of the colliculus lesion apparent either in the group effects or in the interaction.

The lesion had substantial effect on eye fixations. In the first trial (Fig. 1), three SC animals did not respond at all, and only one was in the normal range $(F=16.12$, $\mathrm{df}=1 / 14)$. The latter animal had the smallest lesion of the group. Over their 5 -sec intervals, the group curves were parallel.

This initial difference between groups was eliminated when the control group habituated to the stimulus, as shown in Fig. 2. The interaction was statistically significant $(F=6.50, \mathrm{df}=5 / 70)$.

$$
\text { DISCUSSION }
$$

Though kittens rather than adult cats and a different stimulus combination were used in this experiment, it does confirm the findings of Dreher et al (1965) that SC lesions substantially interfere with the eye-fixation aspect of the orienting response. However, it also showed that elimination of one aspect of the orienting response need not affect all mechanisms since, in the SC animals, heart and respiration responses were apparently normal.

It was necessary to add a buzzer to the light stimulus in order to obtain reliable responding of kittens of the age used. This confounded the effect of light and sound in this study. Therefore, not much can be said about which aspects of the stimulus produced the eye-fixation, heart, and respiration responses. However, the study does permit one to conclude that the SC lesion eliminated eye-fixation responses to combined light and sound stimuli. This has some significance when it is considered that a head-turning response can be elicited by sound alone (Thompson \& Welker, 1963).

Speedy habituation of the eye-fixation response occurred in the normal animals, while the operated animals did not habituate. This differential habituation was undoubtedly an artifact resulting from the initially low level of fixations in the experimentals.

\section{REFERENCES}

DREHER, B., MARCHIAFAVA, P. L., \& ZERNICKI, B. Studies of the visual fixation reflex: II. The neural mechanism of the fixation reflex in normal and pretrigeminal cats. Acta Biologica Experimentalis (Warsaw), $1965,25,207.217$.

THOMYSUN, W. R., \& WELKER, W. l. Role of auditory cortex in reflex head orientation by cats to auditory stimuli. Journal of Comparative \& Physiological Psychology, $1963,56,996-1002$. NOTE

1. This research was supported in part by a grant from the National Institute of Chijd Health and Human Development (HD-01030). 